\title{
ON VACATION MODELS WITH FINITE CAPACITY
}

\author{
Submitted for publication to the \\ Journal of Applied Mathematics and Stochastic Analysis \\ J. LORIS-TEGHEM \\ University of Mons-Hainaut, Department of Applied Mathematics \\ Place Warocqué 17, B-7000 Mons, Belgium \\ E-mail: Jacqueline.Loris@umh.ac.be \\ Fax: (32) 65373054
}

(Received: December 1999)

Key words and phrases: Finite Capacity Queue, General Vacation Policy, Queue Length.

AMS subject classifications: $60 \mathrm{~K} 25$.

Contrary to what is asserted in Frey and Takahashi [1], these authors were not the first to consider the departure epochs imbedded Markov chain for vacation models with finite capacity. In our paper [2], which deals with a general vacation policy, we express the stationary queue length distribution immediately after a departure in terms of the corresponding distribution in the model without vacations.

In [2], we also express the stationary queue length distribution at an arbitrary epoch in terms of the corresponding distribution in the model with vacations. From these two relations, one can easily derive (see [3]) the expression of the stationary queue length distribution at an arbitrary epoch in terms of the stationary queue length distribution immediately after a departure. With the notations used in [2], this expression is:

$$
\begin{gathered}
p_{v, \nu}^{L}(j)=\prod_{v, \nu}^{L}(j) \frac{\lambda^{-1}}{E(S)+d_{v, \nu}^{L} \prod_{v, \nu}^{L}(\nu)}(j=\nu, \ldots, L-1) \\
p_{v, \nu}^{L}(L)=1-\frac{\lambda^{-1}}{E(S)+d_{v, \nu}^{L} \prod_{v, \nu}^{L}(\nu)} .
\end{gathered}
$$

This result contains as a particular case, the expression for the stationary queue length distribution at an arbitrary epoch given in [1], for the exhaustive service multiple vacation policy. 


\section{References}

[1] Frey, A. and Takahashi, Y., A note on the M/GI/1/N queue with vacation time and exhaustive service discipline, Oper. Res. Letters 21 (1997), 95-100.

[2] Loris-Teghem, J., Vacation policies in an M/G/1 type queue system with finite capacity, Queueing Systems 3 (1988), 41-52.

[3] Loris-Teghem, J., On finite capacity queueing systems with a general vacation policy, Technical Report (1998). 


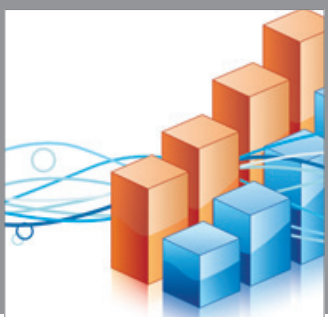

Advances in

Operations Research

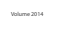

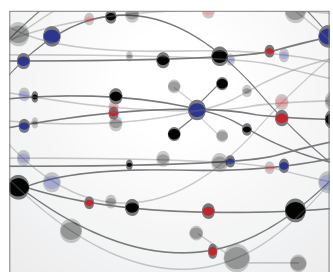

\section{The Scientific} World Journal
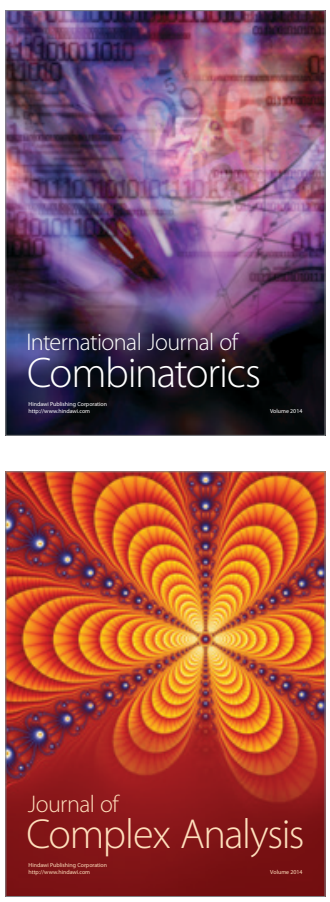

International Journal of

Mathematics and

Mathematical

Sciences
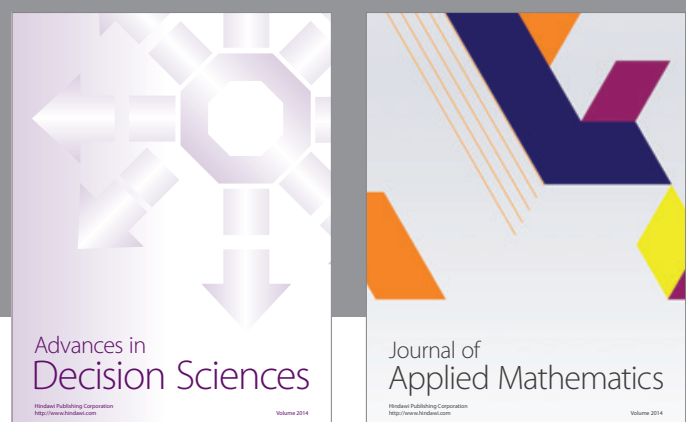

Journal of

Applied Mathematics
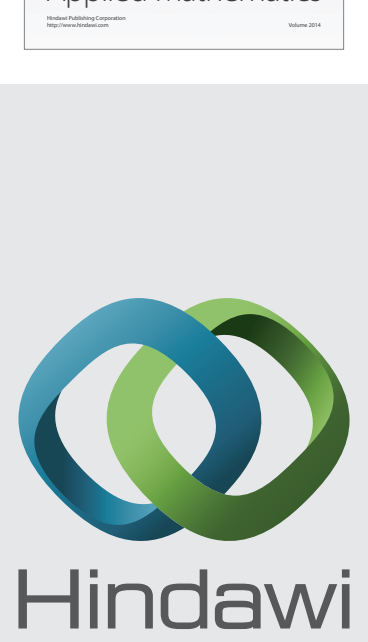

Submit your manuscripts at http://www.hindawi.com
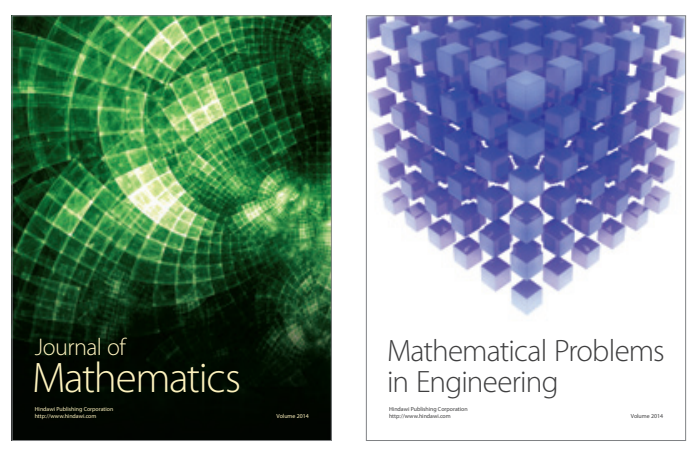

Mathematical Problems in Engineering
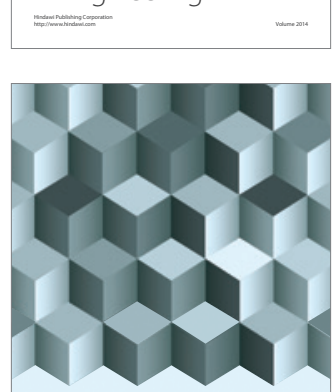

Journal of

Function Spaces
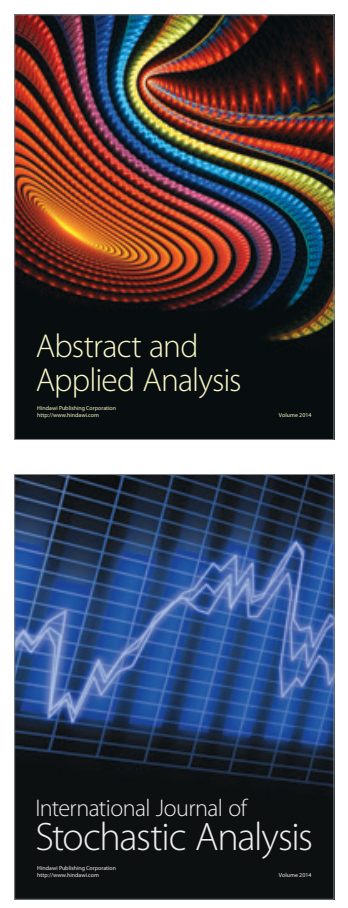

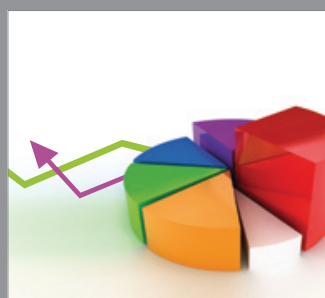

ournal of

Probability and Statistics

Promensencen
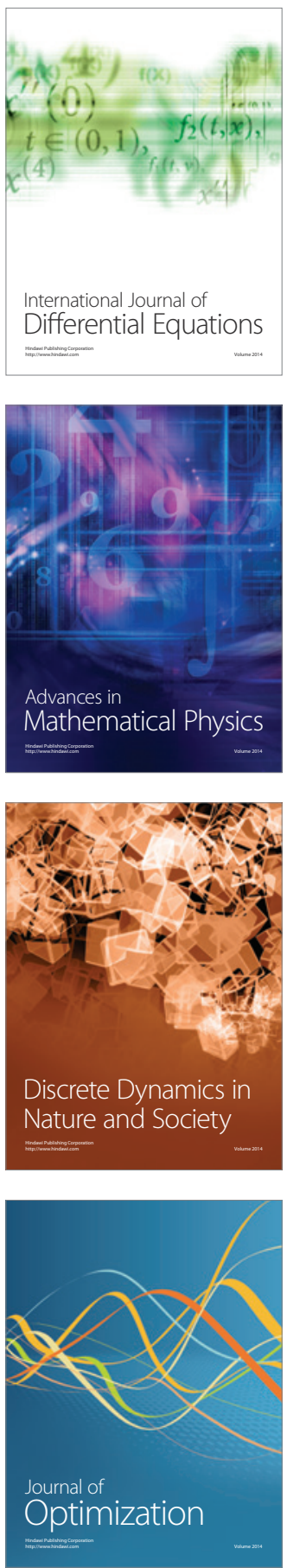